\title{
Publication Only
}

\section{Genomics, genetic basis of disease and functional genomics}

\section{$\mathrm{AB} 0001$ \\ INTERFERON SIGNATURE IN CHILDREN WITH CHRONIC NON-BACTERIAL OSTEOMYELITIS AND IT'S DYNAMIC AFTER BISPHOSPHONATES TREATMENT}

M. Kostik ${ }^{1}$, R. Raupov ${ }^{1}$, R. Mulkidzhan ${ }^{2}$, A. Kosmin ${ }^{2}$, E. Suspitsin ${ }^{1,2}$. ${ }^{1}$ SaintPetersburg State Pediatric Medical University, Hospital Pediatry, SanktPeterburg, Russian Federation; ${ }^{2}$ N.N.Petrov Institute of Oncology, Molecular Diagnostics, Saint-Petersburg, Russian Federation

Background: Chronic non-bacterial osteomyelitis (CNO) is an immune-mediated chronic inflammatory bone disease which predominantly affects children and adolescents. The pathogenesis of CNO related to imbalance between pro-inflammatory and anti-inflammatory cytokines. Interferon-I mediated pathway is associated with pathogenesis of different pediatric rheumatic diseases, such as juvenile systemic lupus erythematosus (jSLE), juvenile dermatomyositis (JDM), systemic onset of juvenile idiopathic arthritis (SoJIA), and, most of all, with macrophage activation syndrome. The data on interferon-I- regulated pathway in CNO is absent. NSAIDs, non-biologic and biologic anti-inflammatory drugs and bisphosphonates (BF) are treatment options for patients with $\mathrm{CNO}$. The main adverse event of $\mathrm{BF}$ is a flu-like syndrome probably caused by the excessive cytokine release stimulated by BF. Objectives: The aim of our study was to evaluate activity of Interferon-I mediated pathway in CNO patients and it's dynamics after BF treatment.

Methods: This prospective study included children with $\mathrm{CNO}$ requiring $\mathrm{BF}$ treatment $(n=9)$, patients with soJIA $(n=8)$, JDM $(n=11)$ and jSLE $(n=40)$ and healthy controls (HC, $n=21$ ). The activity of Interferon-I mediated pathway was assessed using interferon I score (IFN1 score). The score represented the median expression of 5 IFN1-regulated genes (IFI44L, IFI44, IFIT3, LY6E, MX1) measured by quantitative realtime PCR. Patients with $\mathrm{CNO}$ were treated with standard 3-day regimen $(1 \mathrm{mg} / \mathrm{kg} /$ day). We measured interferon score before pamidronate (Day 0, n=9) and after (Day $3, n=7$ ). Results: Median interferon score was $1.09(0.96 ; 1.67)$ in CNO patients, 1.95 $(1.3 ; 5.75)$ in soJIA, $7.6(1.78 ; 29.0)$ in JDM and $16.9(2.55 ; 40.3)$ in jSLE and $0.95(0.82 ; 1.17)$ in $\mathrm{HC}(\mathrm{p}=0.00001)$. Where were no difference in the IFN1 score between $\mathrm{CNO}$ and $\mathrm{HC}(\mathrm{p}=0.222)$. In $6 / 7 \mathrm{CNO}$ patients interferon score increased after pamidronate $(p=0.015)$. The median interferon score after pamidronate increased and became $3.06(0.87 ; 4,9, p=0.043)$; this may possibly explain the development of BF-related flu-like symptoms (cytokine release syndrome).

Conclusion: While interferon I-regulated pathway is not directly associated with CNO pathogenesis, BF likely activates interferon-I-regulated pathway and thus could be a possible cause of flu-like syndrome.

This work supported by the Russian Foundation for Basic Research (grant № 18-515-57001)

Disclosure of Interests: None declared

DOI: 10.1136/annrheumdis-2021-eular.508

\begin{tabular}{|l|l}
\hline AB0002 & ASSOCIATION OF C1Q GENETIC POLYMORPHISMS \\
WITH SUSCEPTIBILITY TO RHEUMATOID ARTHRITIS \\
IN BULGARIAN COHORT
\end{tabular}

M. Kosturkova ${ }^{1}$, G. Mihaylova ${ }^{2}$, M. Radanova ${ }^{2}{ }^{1}$ Varna Medical University, Propedeutics of Internal Diseases, Varna; ${ }^{2}$ Varna Medical University, Biochemistry, Molecular Medicine and Nutrigenomics, Varna, Bulgaria

Background: Complement is strongly implicated in the pathogenesis of autoimmune diseases like systemic lupus erythematosus (SLE) and rheumatoid arthritis (RA). Its component $\mathrm{C} 1 \mathrm{q}$ plays a dualistic role, triggering the inflammatory cascade on one hand and directing the clearance of immune complexes on the other. Homozygous genetic deficiency of C1q is strongly associated with SLE and SLE-like phenotype as almost $90 \%$ of C1q deficient individuals develop SLE or similar disease. Nevertheless, there are few and inconsistent studies exploring the single nucleotide polymorphisms (SNPs) of the C1q gene cluster in relation to the pathogenesis of SLE and RA.

Objectives: The aim of the study was to evaluate the possible association of five SNPs - rs292001, rs172378, rs294179, rs665691 and rs682658 in complement C1q gene cluster with susceptibility to SLE and RA in Bulgarian cohort.

Methods: Fifty patients with SLE, sixty-one patients with RA and sixty-seven healthy controls were genotyped for the five SNPs by TaqMan allelic discrimination assay.

Results: Frequency of genotypes and alleles of rs294179, rs665691 and rs682658 SNPs was similar between patients with SLE, RA and healthy controls. For rs172378 SNP, the minor $\mathrm{G}$ allele $(\mathrm{OR}=2.73 ; 95 \% \mathrm{Cl}, 1.59-4.67, \mathrm{p}=0.0003$ ) and $G G$ genotype $(\mathrm{OR}=5.12 ; 95 \% \mathrm{Cl}, 1.60-16.49, \mathrm{p}=0.006)$ were associated with susceptibility to RA. In our cohort in accordance with others, AA rs292001 SNP genotype was associated with increased risk for RA $(\mathrm{OR}=3.32 ; 95 \% \mathrm{Cl}$ 1.19-9.20, $p=0.021$ ). For SLE patients, AA rs292001 SNP genotype was low presented and did not associate with disease.

Conclusion: GG genotype of rs172378 SNP in C1q gene cluster could be considered as a new risk factor for RA.

\section{REFERENCES:}

[1] Diane Scott et al (2016). The paradoxical roles of C1q and C3 in autoimmunity. Immunobiology, 719-25. doi:10.1016/j.imbio.2015.05.001.

[2] Giles $\mathrm{JL}$ et al (2015). Functional analysis of a complement polymorphism (rs17611) associated with rheumatoid arthritis. J Immunol., 3029-34. doi:10.4049/jimmunol.1402956.

[3] Holers, V. M. (2018). Complement in the Initiation and Evolution of Rheumatoid Arthritis. Frontiers in immunology, 1057. doi:10.3389/ fimmu.2018.01057.

[4] Lintner, K. E. (2016). Early Components of the Complement Classical Activation Pathway in Human Systemic Autoimmune Diseases. Frontiers in immunology, 36. doi:10.3389/fimmu.2016.00036.

[5] Lu, J. \&. (2017). C1 Complex: An Adaptable Proteolytic Module for Complement and Non-Complement Functions. Frontiers in immunology, 592. doi:10.3389/fimmu.2017.00592.

[6] Manderson, A. P. (2004). The role of complement in the development of systemic lupus erythematosus. Annual review of immunology, 431-456. doi:10.1146/annurev.immunol.22.012703.104549.

[7] Martens, H. A. (2009). Analysis of C1q polymorphisms suggests association with systemic lupus erythematosus, serum $\mathrm{C} 1 \mathrm{q}$ and $\mathrm{CH} 50$ levels and disease severity. Annals of the rheumatic diseases, 715-720. doi:10.1136/ ard.2007.085688

[8] Namjou B, G.-M. C. (2009). Evaluation of C1q genomic region in minority racial groups of lupus. Genes Immun., 517-24. doi:10.1038/gene.2009.33

[9] Radanova $\mathrm{M}$ et al(2015). Association of rs172378 C1q gene cluster polymorphism with lupus nephritis in Bulgarian patients. Lupus, 280-9. doi:10.1177/0961203314555173.

[10] Rafiq $S$ et al (2010). Assessing association of common variation in the $C 1 Q$ gene cluster with systemic lupus erythematosus. Clin Exp Immunol., 284-9. doi:10.1111/j.1365-2249.2010.04185.x.

[11] Schejbel $L$ et al (2011). Molecular basis of hereditary C1q deficiency-revisited: identification of several novel disease-causing mutations. Genes mmun., 626-634.

[12] Trouw LA et al (2013). Genetic variants in the region of the C1q genes are associated with rheumatoid arthritis. Clin Exp Immunol., 76-83. doi:10.1111/ cei.12097.

[13] Trouw L. A. (2017). The complement system as a potential therapeutic target in rheumatic disease. Nature reviews. Rheumatology, 538-547. doi:10.1038/ nrrheum.2017.125.

[14] Walport M. J. (2002). Complement and systemic lupus erythematosus Arthritis research, S279-S293. doi:10.1186/ar586.

Disclosure of Interests: None declared

DOI: 10.1136/annrheumdis-2021-eular.989

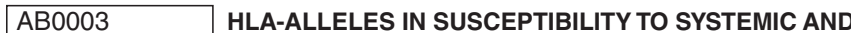 OLIGOARTICULAR JUVENILE IDIOPATHIC ARTHRITIS IN THE BELARUSIAN POPULATION}

H. Yatskiu ${ }^{1}$, A. Sukalo ${ }^{2}$, R. Goncharova ${ }^{1}{ }^{1}$ Institute of Genetics and Cytology of NAS of Belarus, Laboratory of Molecular Basis of Genomic Stability, Minsk, Belarus, ${ }^{2}$ Belarusian State Medical University, 1 st Department of Pediatric Diseases, Minsk, Belarus

Background: Juvenile idiopathic arthritis (JIA) is a complex trait, the most common rheumatic disease in children. Considering clinical heterogeneity of the disease, the genetic background of particular JIA subtypes may also vary significantly.

Objectives: This work was aimed to reveal characteristic patterns of HLA associations within 11 loci for two clinically different forms of JIA in the Belarusian population.

Methods: 24 patients diagnosed with systemic JIA, 24 patients with oligoarticuIar JIA and 24 healthy controls were included into the study. The JIA patients were divided into subgroups according to IIAR classification criteria. High-throughput HLA typing was performed using TruSight HLA v2 Sequencing Panel (Illumina) on MiSeq system. Sample analysis was performed using Assign TruSight HLA v2.0 software.

Results: $D Q A 1^{*} 05: 01: 01$ and $D Q B 1^{*} 02: 01: 01$ alleles showed protective effect against both systemic $(\mathrm{p}=0.007 ; \mathrm{OR}=0.08 ; 95 \% \mathrm{Cl}=[0.009$ $0.65]$ and $\mathrm{p}=0.01 ; \mathrm{OR}=0.09 ; 95 \% \mathrm{Cl}=[0.01-0.83])$ and oliarticular $\mathrm{JIA}$ 